\title{
CHARACTERIZATION OF BIOCOMPOSITES FROM POLYLACTIC ACID AND CELLULOSE OF OIL PALM EMPTY FRUIT BUNCH
}

\author{
Tika Paramitha $^{1, \star}$ and Johnner P. Sitompul ${ }^{2}$ \\ ${ }^{1}$ Department of Chemical Engineering, Faculty of Engineering, Universitas Sebelas Maret \\ Jl. Ir. Sutami No.36A, Surakarta, Central Java 57126, Indonesia \\ ${ }^{2}$ Department of Chemical Engineering, Faculty of Industrial Technology, Institut Teknologi Bandung \\ J. Ganesha No.10, Bandung, West Java 40132, Indonesia \\ *Correspondence: e-mail : tikaparamitha@staff.uns.ac.id
}

\section{ABSTRACT}

Biocomposites are polymers reinforced with natural fibers, such as cellulose. This research aims to synthesize cellulose from Oil Palm Empty Fruit Bunch (OPEFB) and biocomposites from PLA and cellulose. In this study, cellulose was obtained through alkalization, hydrolysis, and bleaching of OPEFB. Biocomposites production was carried out by mixing PLA and cellulose using the extrusion method. In the extrusion method, PLA and cellulose of OPEFB were mixed using an extruder above the melting point of PLA of $170^{\circ} \mathrm{C}$. The output product of an extruder was then pressed using a compression moulding machine to form biocomposites. The tensile strength of biocomposites had a smaller value than pure PLA, whereas the modulus young of biocomposites with $5 \%$ by weight of cellulose had a higher value than pure PLA. The decrease in the mechanical properties of biocomposites was caused by poor adhesion between PLA and cellulose. The water absorption of biocomposites was greater than pure PLA, which was influenced by cellulose's characteristics as hydrophilic and PLA is hydrophobic. Also, the higher water absorption in biocomposites accelerated the weight loss of biodegradability.

Keywords: Cellulose, OPEFB, PLA, Biocomposites, Extrusion

\section{INTRODUCTION}

In recent years, composites have rapid development due to the demand for applications in the construction, automotive, aerospace, and packaging industry [1-3]. Composite consists of polymers as matrix and fillers. The characteristic of polymers is lightweight material [1] compared to glass or metal. Also, polymers are easily shaped according to the desired design and size. However, polymers and fillers that cannot degrade naturally by microbes in the soil will cause pollution and damage to the environment. Therefore, biocomposites are developed because its advantages are environmentally friendly and biodegradable.

Polylactic acid (PLA) is one of the biopolymers that are widely used and developed. PLA has advantages of excellent biodegradability, processability, and biocompatibility [4]. PLA can be used as a raw material to produce plastic bags, laminated films, overwrap films, disposable glasses and 
plates, drug delivery systems, suture, and scaffold [5].

The addition of filler into the PLA matrix is interesting because it can increase the biodegradation rate [6]. One type of filler commonly used is cellulose. Cellulose can be obtained from oil palm empty fruit bunch (OPEFB). The cellulose of OPEFB is about $42.7-65 \%$ by weight. Cellulose from OPEFB as a filler is also a solution to increase the value of waste produced by palm oil industries. The characteristics of OPEFB are cheap, low density, high strength, and biodegradable [7].

Several studies on the addition of cellulose to PLA polymers have been done. Harmaen et al. (2003) [8] produced PLAbiocomposites with OPEFB fibres' addition measuring 0.25-0.5 mm. In general, pure PLA shows better tensile strength than PLAbiocomposites, but tensile modulus increases with OPEFB fibres' addition. The use of fiber as a filler [9] The tensile strength of biocomposites decrease at the composition of $40 \%$ by weight of flax fiber. The addition of $30 \%$ by weight of flax fiber has a tensile strength of $53 \mathrm{MPa}$, while pure PLA has a tensile strength of $50 \mathrm{MPa}$. But at the addition of $40 \%$ by weight of flax fiber tensile strength drops to $44 \mathrm{MPa}$. The decrease in biocomposite strength is due to poor adhesion between flax fibers and the polymer matrix. Surface modification of fiber can be used to optimize the adhesion of filler and polymer matrix. Previous studies focused on hydrogen peroxide efficiency as a bleaching agent to remove lignin, hemicellulose, and surface impurities [10]. This article becomes interesting when OPEFB cellulose is prepared using surface modification through chemical and physical routes. This article will also discuss the biocomposite production of PLAcellulose OPEFB and characterization of the mechanical properties, water absorp-tion properties, and weight reduction of the studied biodegradability.

\section{METHODS}

\section{Production of Cellulose from OPEFB}

OPEFB was ground and sieved using a 30 mesh sieve. Then, OPEFB soaked in 0.5 $\mathrm{M} \mathrm{NaOH}$ solution for 1 hour. Afterwards, OPEFB filtered and placed in a hydrothermal reactor. The reaction time was carried out for 30 minutes. OPEFB was further soaked using $\mathrm{NaOCl}$ at $65^{\circ} \mathrm{C}$ with the composition of OPEFB and $\mathrm{NaClO}$ solution of $1: 50(\mathrm{~m} / \mathrm{v})$. The cellulose of OPEFB was filtered, washed until $\mathrm{pH}$ neutral, and dried. OPEFB was ground and sieved again using a 325 mesh sieve.

\section{Production of Biocomposites}

The production process of PLAcellulose biocomposites using the extrusion method. PLA and cellulose were mixed using a magnetic stirrer. Afterwards, the mixture of PLA and cellulose was extruded. The composition variation of cellulose of OPEFB were $0 \%, 5 \%$, and $10 \%$ by weight. The screw temperature of the extruder was $170^{\circ} \mathrm{C}$. The output of the extruder was pelleted. The pellets were then pressed using compression moulding with the pressure of $10 \mathrm{MPa}$ and temperature of $170^{\circ} \mathrm{C}[11]$. 


\section{Characterization of Biocomposites}

Fourier Transform Infrared Spectroscopy (FTIR) Analysis: FTIR analysis was used to identify the presence of functional groups contained in the cellulose of OPEFB. IR spectra were recorded in the spectra range of $4000-500 \mathrm{~cm}^{-1}$ using a Bruker Platinum-ATR type spectrometer at room temperature.

Mechanical Properties Analysis: The mechanical properties of biocomposites were analyzed using Universal Testing Machine (RTF-1310). The tensile test was carried out at a pull speed of $2 \mathrm{~mm} / \mathrm{sec}$ and load of $10,000 \mathrm{~N}$.

Water Absorption Analysis: Biocomposites were cut to size $5 \mathrm{~cm} \times 1 \mathrm{~cm} \times$ thickness. The samples were dried until constant weight. The water absorption analysis was carried out by immersing the water sample at a temperature of $30^{\circ} \mathrm{C}$ for eight days. Then, water in the sample was removed, dried, and weighed.

Biodegradation Analysis: Biocomposites were cut to the size of $5 \mathrm{~cm} \times 1 \mathrm{~cm} \mathrm{x}$ thickness. The initial weight of the samples was weighed. Then, the samples were buried in a compost instrument at $58^{\circ} \mathrm{C}$ [12]. The samples were cleaned to remove impurities on the surface of biocomposites. Subsequently, the samples were dried and weighed at 12,24 , and 36 days.

\section{RESULT AND DISCUSSION}

\section{Fourier Transform Infrared Spectroscopy}

The production of cellulose of OPEFB through a series of processes via chemical and physical route, including alkalization using $\mathrm{NaOH}$, hydrolysis using water at high temperature, and bleaching using $\mathrm{NaOCl}$. The aim of a series of processes is to breakdown lignin bonds. The FTIR results in Figure 1 show the group of cellulose.

The peak in the absorption band of $3,331.55 \mathrm{~cm}^{-1}$ is a hydroxyl group of cellulose. The $-\mathrm{OH}$ group at the peak of about 1,611.85 $\mathrm{cm}^{-1}$ are attributed to the absorption of water by cellulose. The reaction of processes influences the number of $-\mathrm{OH}$ groups in cellulose produced water. Because cellulose is hydrophilic, the water is bound by cellulose which causes the concentration of $-\mathrm{OH}$ groups increase. The absorption band at $2,895.90 \mathrm{~cm}^{-1}$ shows $\mathrm{C}-\mathrm{H}$ stretching. At the peak of about $1,427.20 \mathrm{~cm}^{-1}$ shows the $-\mathrm{CH}_{2}$ bond in cellulose. The bands in the region $1,400-1,300 \mathrm{~cm}^{-1}$ are attributed to the aliphatic and aromatic methyl, methylene, and methoxy groups [8]. The peak indicates lignin between $1,300-1,200 \mathrm{~cm}^{-1}$, which is shown at the peak of $1,201.71 \mathrm{~cm}^{-1}$ for $\mathrm{C}=\mathrm{C}$ aromatic rings and $1,157.20 \mathrm{~cm}^{-1}$ for C-O-C stretching. The appearance of a peak on these frequencies confirmed removing lignin, hemicellulose, and surface impurities through a series of processes not completed.

Tabel 1. Absorption Area of Cellulose

\begin{tabular}{ll}
\hline $\begin{array}{c}\text { Observed Frequency } \\
\left(\mathrm{cm}^{-1}\right)\end{array}$ & \multicolumn{1}{c}{ Vibrations } \\
\hline $3,331.55$ & $\mathrm{O}-\mathrm{H}$ stretching \\
$2,895.90$ & $\mathrm{C}-\mathrm{H}$ stretching \\
$1,611.85$ & $\mathrm{O}-\mathrm{H}$ bending \\
$1,427.20$ & $-\mathrm{CH}_{2}$ deformation \\
$1,317.74$ & $\mathrm{C}=\mathrm{H}$ stretching \\
$1,201.71$ & $\mathrm{C}=\mathrm{C}$ aromatic rings \\
$1,157.20$ & $\mathrm{C}-\mathrm{O}-\mathrm{C}$ stretching \\
$1,031.29$ & $\mathrm{C}-\mathrm{C}$ stretching \\
897.19 & $\mathrm{C}-\mathrm{H}$ deformation \\
\hline
\end{tabular}





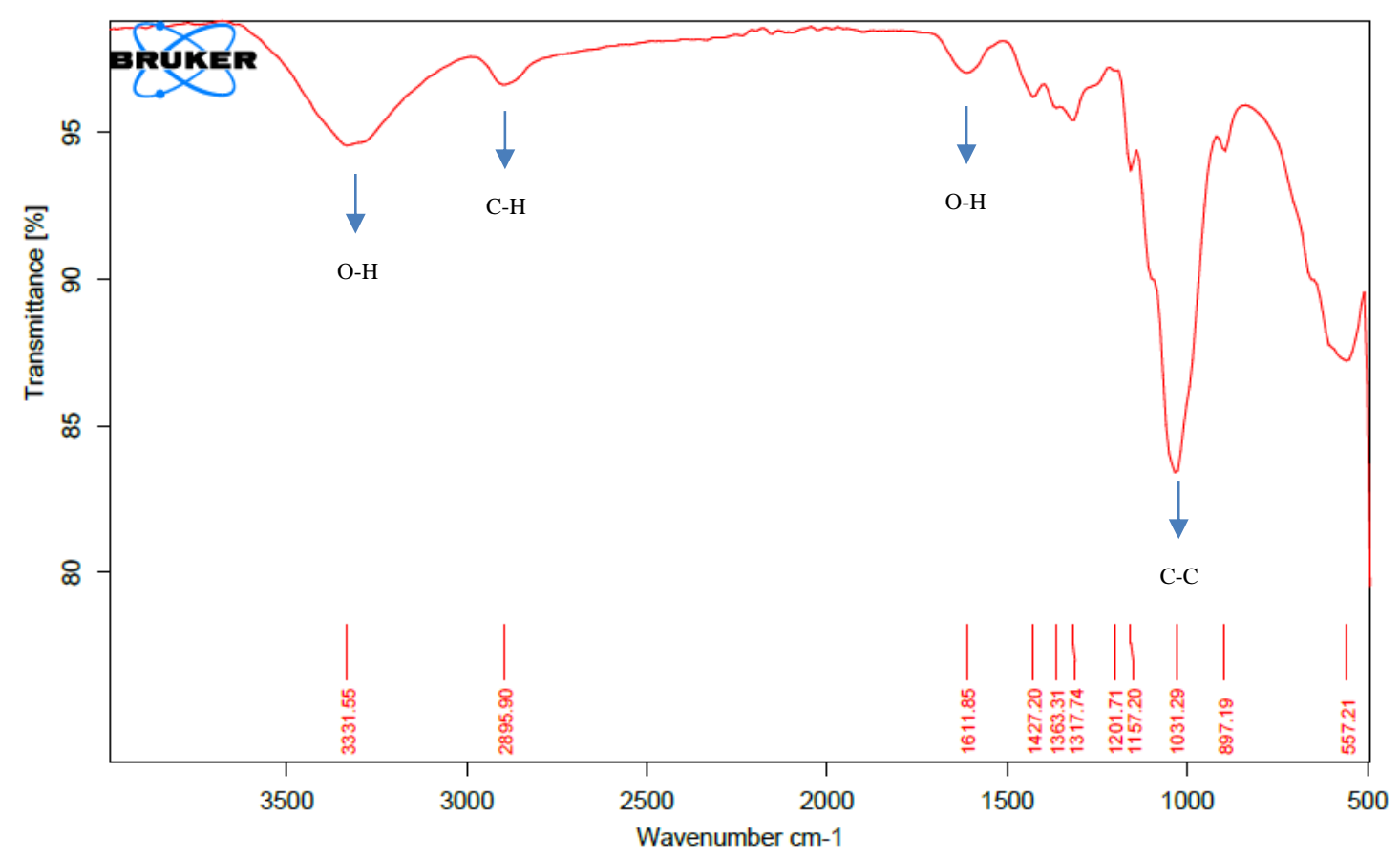

Figure 1. FTIR Spectra of Cellulose

\section{Mechanical Properties}

The mechanical properties of biocomposites are shown in Figure 2. In general, pure PLA has better tensile strength than biocomposites, and the results of these studies are the same as those conducted by Harmaen et al. (2013) [8]. The addition of cellulose (fillers) will have an impact on decreasing The tensile strength of biocomposites. The hydrophilic characteristics of cellulose can reduce biocomposites' mechanical properties due to incompatibility with the hydrophobic polymer matrix. Poor adhesion between cellulose and PLA results in difficult dispersion of cellulose in the PLA matrix and decreased mechanical properties of the biocomposites. Tensile strength of biocomposites with cellulose composition of $10 \%$ by weight decrease by $43.96 \%$ compared to pure PLA because the matrix cannot completely wet out the cellulose [8]. The decrease in tensile strength becomes more drastic in the addition of higher cellulose caused by more filler-filler interactions compared to filler-matrix interactions, resulting in agglomerates of cellulose. Agglomeration of cellulose leads to local stress concentration in the biocomposites. Furthermore, agglomeration reduces the effective cross-sectional area for fillers [13].

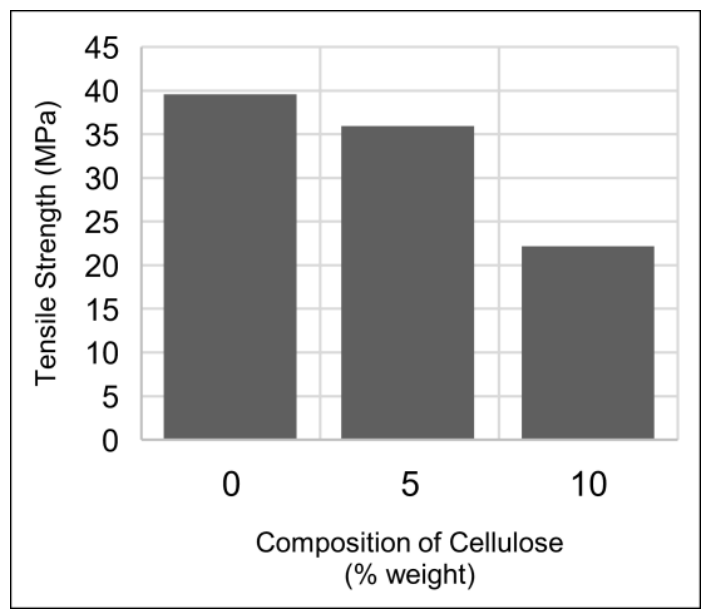

(a) 


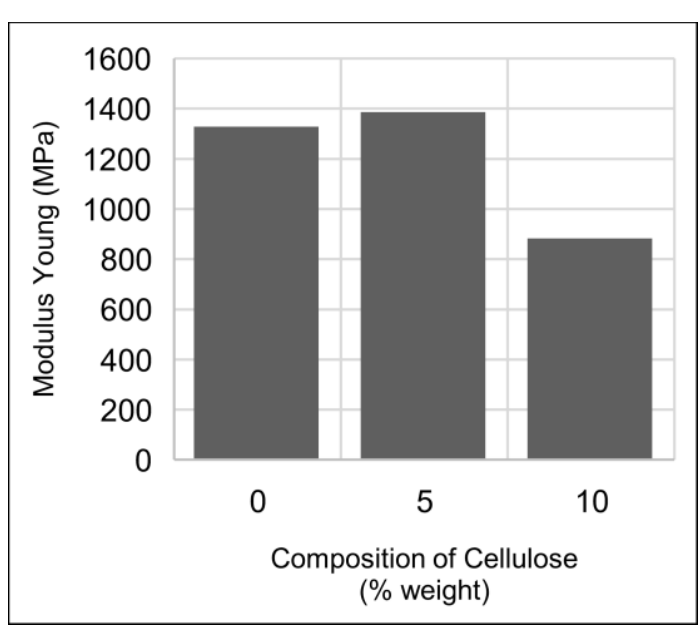

(b)

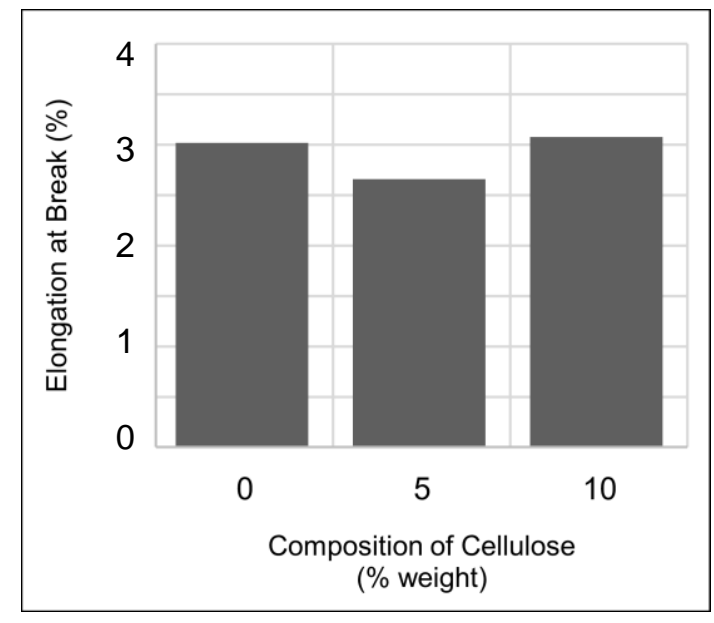

(c)

Figure 2. Effect of Cellulose Composition on Mechanical Properties of Biocomposites (a) Tensile Strength, (b) Modulus Young, (c) Elongation at Break

Biocomposites with the composition of cellulose of $5 \%$ by weight have higher modulus young than pure PLA. The increase in modulus young with cellulose addition indicates that cellulose improves biocomposites' stiffness [14]. On the contrary, biocomposite with a cellulose composition of $10 \%$ by weight has lower modulus young than pure PLA. This is caused by the fillerfiller interaction at the high composition of cellulose. Besides, the filler-filler interaction decreases the ability of cellulose to transmit stress to the polymer matrix.
The elongation of break decreases from 3.02 to 2.66 at $5 \%$ of cellulose and increase from 3.02 to 3.08 at $10 \%$ of cellulose. However, the increase of elongation at break in biocomposite is not significant compared to pure PLA due to the weak interaction between cellulose and PLA. These results are in agreement with those reported by $\mathrm{Ke}$ and Sun (2000) [15] that adhesion between PLA and wheat flour is present, but the interaction is not strong. The interaction between PLA and cellulose is hydrogen bonds between carbonyl groups in PLA and hydroxyl groups in cellulose.

\section{Water Absorption}

The water absorption of biocomposites increases with the addition of cellulose. The results of the water absorption analysis of biocomposites are shown in Figure 3.

Based on the research by Alhuthali et al. (2013) [16], the high aspect ratio of filler can decrease water absorption because the water path is distributed. However, high cellulose composition causes poor dispersion of cellulose. The formation of voids indicates this due to agglomeration of cellulose. These voids will absorb more water molecules to increase the percentage of water absorption [7].

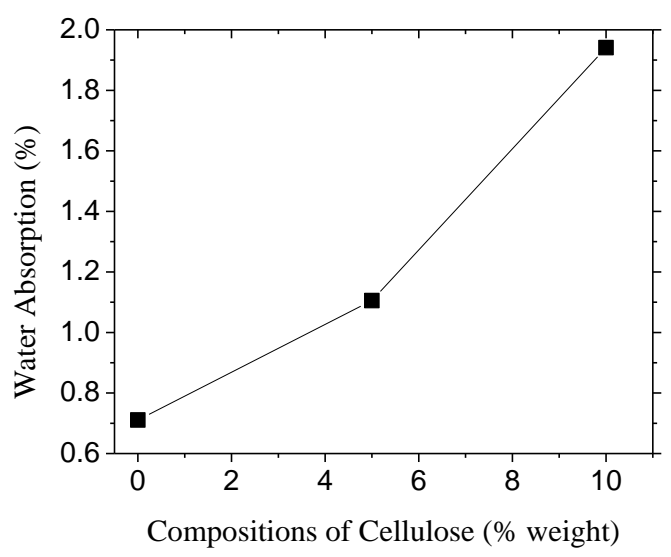

Figure 3. Water Absorption of Biocomposites 
The water absorption is related to the diffusion water rate into the biocomposites the high water absorption in biocomposites due to cellulose's hydrophilic characteristic. Cellulose has many hydroxyl groups which interact with water molecules. Besides, cellulose on the matrix's surface will absorb more water than cellulose in the matrix. Water molecules can saturate on the biocomposites surface and penetrate through a hole, resulting in high water absorption quickly.

\section{Biodegradability}

The amount of cellulose influences the weight loss of biodegradability in biocomposite. Surface erosion indicates the level of biodegradation that occurs in biocomposites [17]. Figure 4. shows the percentage of weight loss from biodegradation using a compost instrument.

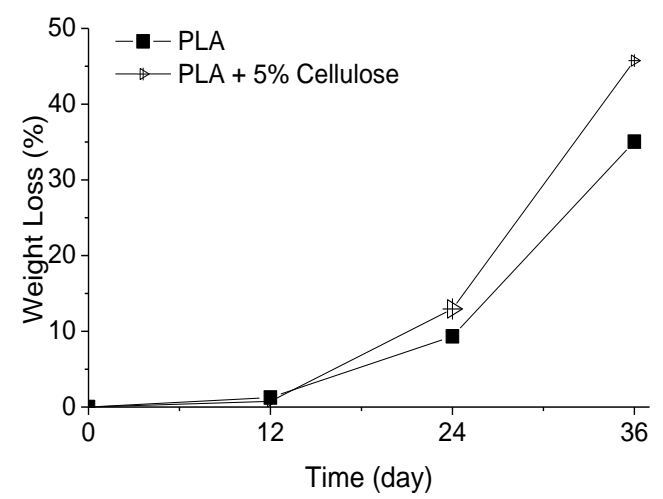

Figure 4. The weight loss of Biocomposites

The weight loss of biocomposites is greater than pure PLA, and This is because the characteristic of PLA is hydrophobic, which has a low affinity for water. Besides, pure PLA has a semicrystalline structure with resistance to enzymatic activity due to high molecular interactions. On the other hand, the characteristic of cellulose is hydrophilic.
So, the rapid rate of water absorption on biocomposite (PLA $+5 \%$ cellulose) resulting in rapid biodegradation.

\section{CONCLUSION}

cellulose will affect mechanical properties, water absorption, and weight loss biodegradability of biocomposites. Tensile strength of biocomposites with cellulose composition of $10 \%$ by weight decrease by $43.96 \%$ compared to pure PLA. However, biocomposite with cellulose composition of $5 \%$ by weight has higher modulus young than pure PLA. The water absorption in all of the samples of biocomposites is greater than in pure PLA. Furthermore, water absorption influences the weight loss of biodegradability. The high rate of water absorption resulting in the high weighs loss of biodegradability.

\section{REFERENCES}

[1] O. Faruk, A. K. Bledzki, H. P. Fink, and M. Sain, "Biocomposites reinforced with natural fibers: 2000-2010," Progress in Polymer Science, vol. 37, pp. 1552-1596, 2012.

DOI:10.1016/j.progpolymsci.2012.04. 003

[2] M. S. Huda, L. T. Drzal, M. Misra,A. K. Mohanty, K. Williams, and D. F. Mielewski, "A Study on Biocomposites from Recycled Newspaper Fiber and Poly(lactic acid)," Ind. Eng. Chem. Res., vol. 44, pp. 5593-5601, 2005. DOI:10.1021/ie0488849

[3] T. Gurunathan, S. Mohanty, and S. K Nayak, "A review of the recent developments in biocomposites based on natural fibres and their application perspectives," Composites: Part A, vol. 77, pp. 1-25, 2015.

DOI:10.1016/j.compositesa.2015.06.0 07 
[4] M. Râpă, A. C. Miteluţ, E. Tănase, E.Grosu, P. Popescu, M. E.Popa, and C.Vasile, "Influence of chitosan on mechanical, thermal, barrier and antimicrobial properties of PLAbiocomposites for food packaging," Composites Part B: Engineering, vol. 102, pp. 112-121, 2016.

DOI:10.1016/j.compositesb.2016.07.016

[5] L. Averous, "Polylactic Acid: Synthesis, Properties and Applications," Monomers, Polymers and Composites from Renewable Resources, pp. 433-450, 2008.

DOI:10.1016/B978-0-08-045316-3.00021-1

[6] E.Ozdemir, T. O. Lekesiz, and J. Hacaloglu, "Polylactide/organically modified montnorillonite composites; effects of organic modifier on thermal characteristics," Polymer Degradation and Stability, vol. 134, 87-96, 2016.

DOl:10.1016/.jpolymdegradstab.2016.09.028

[7] N. S.Lani, N. Ngadi, A. Johari, and M. Jusoh, "Isolation, Characterization, and Application of Nanocellulose from Oil Palm Empty Fruit Bunch Fiber as Nanocomposites," Journal of Nanomaterials, vol. 2014, pp. 1-9, 2014. DOI:10.1155/2014/702538

[8] A. S. Harmaen, A. Khalina, A. R. Faizal, and M. Jawaid, "Effect of triacetin on tensile properties of oil palm empty fruit bunch fiber-reinforced polylactic acid composites," PolymerPlastics Technology and Engineering, vol. 52, pp. 400-406, 2013.

DOI:10.1080/03602559.2012.754897

[9] K. Oksman, M. Skrifvars, and J. F. Selin, "Natural fibres as reinforcement in polylactic acid (PLA) composites," Composites Science and Technology, vol. 63, pp. 1317-1324, 2003.

DOI:10.1016/S0266-3538(03)00103-9

[10] M. Rayung, N. A. Ibrahim, N. Zainuddin, W. Z. Saad, N. I. A. Razak, and B. W. Chieng., "The effect of fiber bleaching treatment on the properties of poly(lactic acid)/oil palm empty fruit bunch fiber composites," International Journal of Molecular Sciences, vol. 15, pp. 14728-14742, 2014. DOI:10.3390/ijms150814728

[11] W. S.Chow, Y.Y Leu, and Z. A. Mohd Ishak, "Water absorption of poly(lactic acid) nanocomposites: effects of nanofillers and maleated rubbers," Polymer-Plastics Technology and Engineering, vol. 53, pp. 858-863, 2014. DOI:10.1080/03602559.2014.886054

[12] T. Paramitha, V. Wonoputri, D. S. D. Sitompul, H. W. Lee, and J. P. Sitompul., "Properties of clays reinforced PLA nanocomposites by melt extrusion technique," Malaysian Journal of Fundamental and Applied Sciencies, vol. 16, pp. 453-457, 2020. DOI:10.11113/mjfas.v16n4.1534

[13] S. S. Ray, K. Yamada, M. Okamoto, and K. Ueda., "Control of biodegradability of polylactide via nanocomposite technology," Macromolecular Materials and Engineering, vol. 288, pp. 203-208, 2003.

DOI:10.1002/mame.200390013

[14] Z. M. Ishak, A. Aminullah, H. Ismail, and H. D. Rozman, "Effect of silanebased coupling agents and acrilic acid based compatibilizers on mechanical properties of oil palm empty fruit bunch filled high-density polyethylene composites," Journal of Applied Polymer Science, vol. 68, pp. 2189-2203, 1997. DOI:10.1002/(SICl)10974628(19980627)68:13<2189::AIDAPP16>3.0.CO;2-V

[15] T. Y. Ke and X. Z. Sun, "Physical properties of poly(lactic acid) and starch composites with various blending ratios," Cereal Chem, vol. 77, pp. 761-768, 2000.

DOI:10.1002/(SICI)10974628(19980627)68:13<2189::AIDAPP16>3.0.CO;2-V

[16] A. Alhuthali, I. M. Low, and C. Dong, "Characterization of the water absorption, mechanical and thermal properties of recycled cellulose fibre reinforces vinylester-eco-nanocomposites," Composites Part B: Engineering, vol. 43, pp. 27722781, 2012. DOI:10.1016/j.compositesb.2012.04.038

[17] G. H. Yew, A. M. Yusof, Z. M. Ishak, and U. S.Ishiaku, "Water absorption and enzymatic degradation of poly(lactic acid)/rice starch composites," Polymer Degradation and Stability, vol. 90, pp. 488-500, 2005.

DOl:10.1016/.jpolymdegradstab.2005.04.006 